\title{
Multi-domain Modeling and Robust Design of Hydraulic Shock Absorber
}

\author{
Peng Manlong ${ }^{1}$, Ling Feng ${ }^{1,2}$, Fu Wenkui ${ }^{1}$, Zhang Yunqing ${ }^{1}$ \\ 1. Huazhong University of Science \&Technology, Wuhan, China \\ 2. Ordnance Noncommissioned Officer School, Wuhan, China \\ e-mail: pengmanlong126@yahoo.com.cn
}

\begin{abstract}
In this paper, a suspension with spring and Hydraulic shock absorber model is presented with AMESim software. Hydraulic shock absorber model contains piston valve assembly, bottom valve assembly, rebound chamber, compression chamber, reserve chamber and so on. Then the optimal parameters of the Hydr-aulic shock absorber are determined using $6 \sigma$ robust optimization method. Finally, the performance of original parameters, deterministic optimizing param-eters and robust optimizing parameters are compared. The result indicates the $6 \sigma$ robust optimization method can greatly improve the property of the Hydr-aulic shock absorber.
\end{abstract}

Keywords-Hydraulic shock absorber, Robust design, AMESim modeling

\section{INTRODUCTION}

All manuscripts must be in English. These guidelines include complete descriptions of the fonts, spacing, and related information for producing your proceedings manuscripts. Please follow them and if you have any questions, direct them to the production editor in charge of your proceedings at Conference Publishing Services (CPS): Phone +1 (714) 821-8380 or Fax +1 (714) 761-1784.

Hydraulic shock absorber(HSA) is one of the most important and complex elements in a vehicle suspension system. There are two approaches to modeling shocks, one is analytical modeling based on physical and geometrical data, the other is parametric modeling based on experimental data [1]. The parametric modeling is simply suitable for some certain situation.

There are some complex analytical HSA models developed by researchers, such as Lang' model [2] and Morman' model [3]. However, they are very complex thus merely be used in research. So it's very necessary to build a completely and simply model based on multi-domain. In this paper, a suspension with spring and HSA model was established based on AMESim, and $6 \sigma$ robust optimization method was used to improve the property of the HSA.

\section{TheORY Of Robust Design}

There are some methods to estimate reliability, such as Monte Carlo methods[4] and Reliability-based optimization methods. There is an additional method called Robust Design which can improve both the reliability and the standard deviation of the mean.

Two famous robust methods mostly used by researchers is Taguchi robust design and $6 \sigma$ robust design. According to Dr. Taguchi[5], robustness is defined as "A state of insensitivity of the functional performance of a product or a process to variations in raw material, manufacturing processes and operating environment over its intended useful life".

Considering only a small amount of factors of robust design described in following sections, then the $6 \sigma$ method is more suitable for this situation. Figure1 shows the basic optimization principal of $6 \sigma$ method.

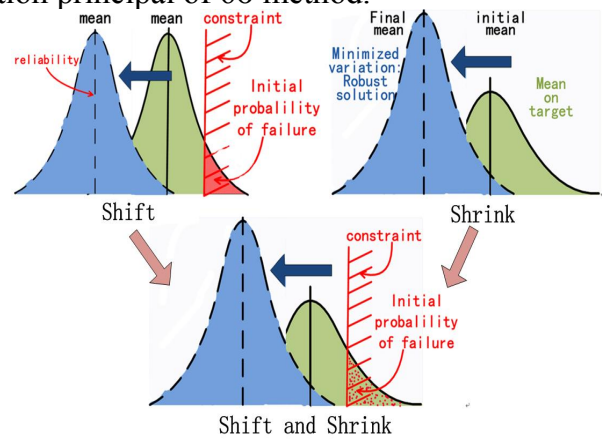

Figure 1. the basic optimization principal of $6 \sigma$ method

$6 \sigma$ design is an optimization method which makes the mean and standard deviation of objective function as appropriate as possible. The optimization model can be expressed as:

Minimize: $\mathrm{F}\left(\mu_{\mathrm{y}}(\mathrm{x}), \sigma_{\mathrm{y}}(\mathrm{x})\right)$

Subject to: $G_{j}\left(\mu_{y}(x), \sigma_{y}(x)\right) \leq 0, j=1,2, \cdots, M$

$x_{L i}+n \sigma_{x_{i}} \leq \mu_{x_{i}} \leq x_{U i}-n \sigma_{x_{i}}, i=1,2, \cdots, N$;

Generally, $\mathrm{F}(\mathrm{x})$ is expressed as:

$$
\mathrm{F}=\sum_{\mathrm{i}=1}^{\mathrm{L}}\left(\frac{\mathrm{w}_{1 \mathrm{i}}}{\mathrm{s}_{1 \mathrm{i}}}\left(\mu_{\mathrm{yi}}-\mathrm{T}_{\mathrm{i}}\right)^{2}+\frac{\mathrm{w}_{2 \mathrm{i}}}{\mathrm{s}_{2 \mathrm{i}}} \sigma_{\mathrm{yi}}^{2}\right)
$$

\section{The Modeling Of HydraUlic SHOck AbsORber}

\section{A. Physical structure}

In working condition, the piston valve assembly and the bottom valve assembly are used. The fluid paths are shown in the Figure 2. 


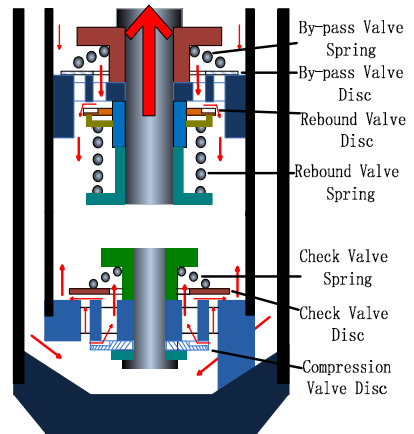

a. The rebound stage

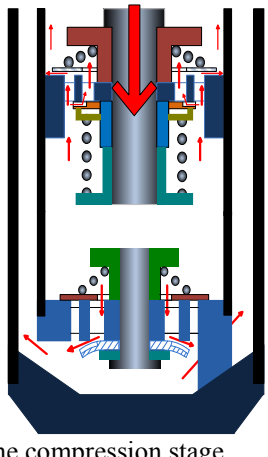

b. The compression stage
Figure 2. Two working conditions of the HSA

According to the structure described above, the piston valve assembly model and the bottom valve assembly model are built in AMESim software environment.

\section{B. Piston valve assembly model}

The structure of piston valve assembly is shown in Fig 3, and corresponding of piston valve assembly is shown in.

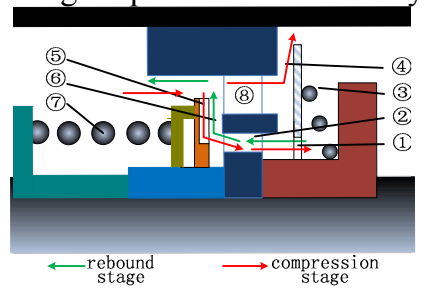

Figure 3. the structure of piston valve assembly

The throttle effect is simulated by a fixed hydraulic orifice signed ' 1 ' in Figure4.

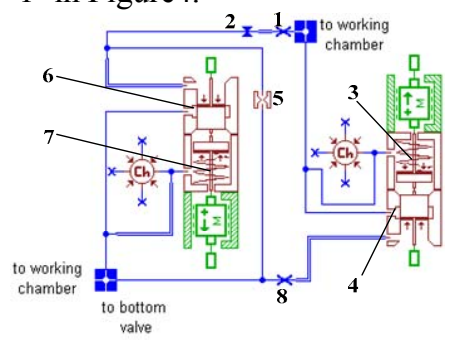

Figure 4. the model of piston valve assembly

\section{Bottom valve assembly model}

The bottom valve assembly includes two valves, the compression valve and the check valve.

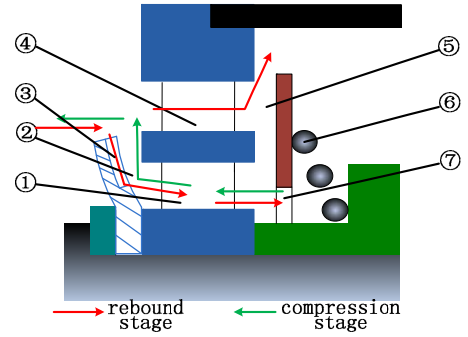

Figure 5. the structure of bottom valve

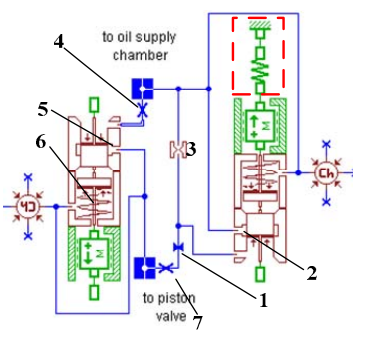

Figure 6. the model of bottom valve

The structure of the bottom valve is shown in Figure 5 and the AMESim model is shown in Figure6. The part signed by red box in Figure6 is simulates the stiffness of compression valve disc, expressed as "PK" in following section.

\section{The overall model}

Figure 7 shows a $1 / 4$ vehicle model including the overall model of the HSA. Two valve assembly models mentioned above consist of the HSA model.

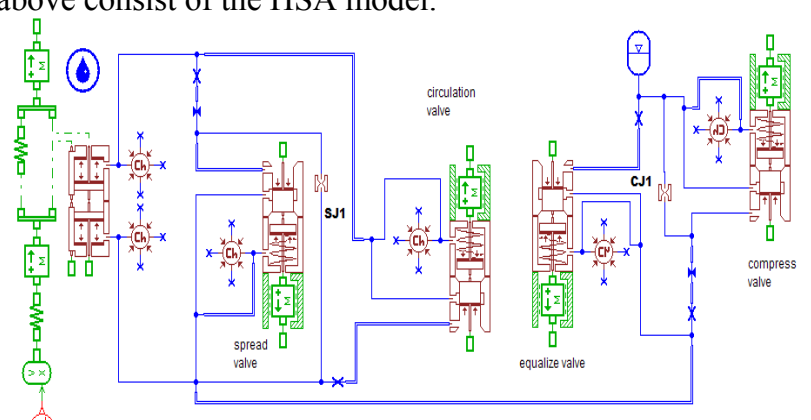

Figure 7. the $1 / 4$ vehicle model

\section{Design VARIABle Selecting}

Variables are selected after researching HSA characteristic curves. Then they be used in sensitivity analysis. The 11 variables are shown in Table.1.

The input signal shown in Figure9(b) is translated from the standard pulse road by considering vehicle velocity. The velocity is $16 \mathrm{Km} / \mathrm{h}$, and the pulse road is shown in Figure9(a).

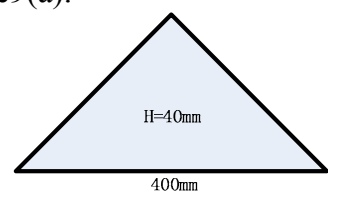

(a)

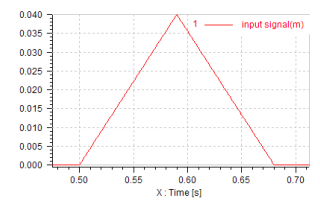

(b)
Figure 8. the standard pulse road block and the input signal in AMESIM

The acceleration (oa), displacement (od) and force (of) between tire and road selected as the objective at sensitivity analysis. The results of sensitivity analysis is shown in Figure10. 


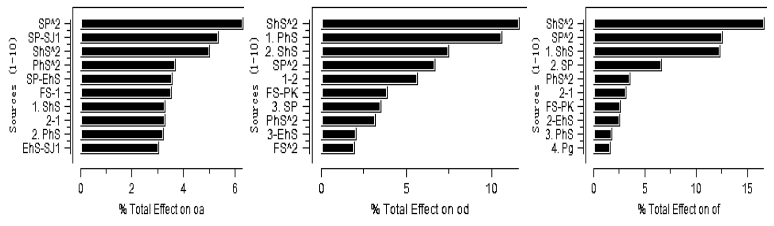

Figure 9. the effects of 11 variables on "oa", "od" and "of"

As is shown in in Figure 10, five variables have a great influence on this three objectives. They are SP, ShS, PhS, FS, $\mathrm{EhS}$ and Pg. The other factors shown in Figure10 is all consisted by these five factors. The five factors will be used as design parameters in robust optimization.

\section{ROBUST OPTIMIZATION}

In order to improve the performance of the vehicle ride comfort as far as possible, we take the vertical acceleration (acc) of bodywork as the objective. The working displacement is maintain within $0.1 \mathrm{~m}$, and the force between tire and ground is greater than $3 \mathrm{kN}$. Then according to $6 \sigma$ robust optimization method, the model is created as following:

$$
\begin{aligned}
& \text { Mnimize } \frac{\mathrm{w}_{\mu}}{\mathrm{S}_{\mathrm{u}}} \mu_{\mathrm{acc}}+\frac{\mathrm{W}_{\sigma}}{\mathrm{S}_{\sigma}} \sigma_{\mathrm{acc}} \\
& \text { Subject to } 6 \sigma_{\text {dis }} \leq \mu_{\text {dis }} \leq 0.1-6 \sigma_{\text {dis }} ; \mu_{\text {foree }} \geq 3000+6 \sigma_{\text {frowe }} ; 11+6 \sigma_{\mathrm{SP}} \leq \mathrm{SP} \leq 17-6 \sigma_{\mathrm{SP}} \text {; } \\
& 1.2+6 \sigma_{\mathrm{StS}} \leq \mathrm{ShS} \leq 5-6 \sigma_{\mathrm{Sth}} ; 1.3+6 \sigma_{\mathrm{PhS}} \leq \mathrm{PhS} \leq 5-6 \sigma_{\mathrm{PhS}} ; \\
& 18+6 \sigma_{\mathrm{FS}} \leq \mathrm{FS} \leq 24-6 \sigma_{\mathrm{FS}} ; 6+6 \sigma_{\mathrm{FS}} \leq \mathrm{EhS} \leq 12-6 \sigma_{\mathrm{FF}} ; 2+6 \sigma_{\mathrm{FS}} \leq \mathrm{Pg} \leq 8-6 \sigma_{\mathrm{FS}} ; \\
& \mathrm{X}_{0}=(S P, S h S, P h S, F S, E h S, P g)^{\mathrm{T}}=(14.8,4.4,1.76,22.1,8,4.5)^{\mathrm{T}} \text {; }
\end{aligned}
$$

The change of parameters in manufacturing and working are considered in all constraints. The standard deviation used in robust design is $\pm 10 \%$. Table 2 compared the valves and $6 \sigma$ level.

The displacement and acceleration curves of bodywork in $1 / 4$ vehicle model are shown in Figure11 and Figure12.

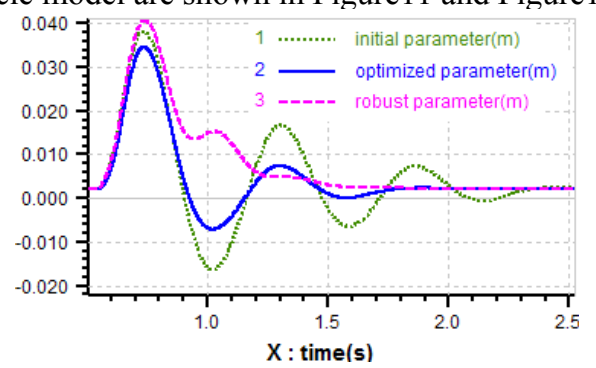

Figure 10. the displacement of bodywork with different parameters

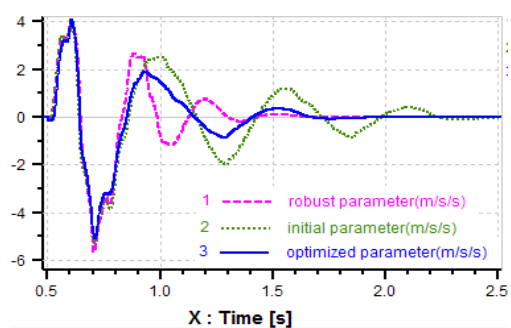

Figure 11. the acceleration of bodywork with different parameters
As is shown in these figures. $6 \sigma$ robust optimization method cannot make all design parameters to achieve $6 \sigma$ level. So this method is just a way to find a coordinate goal between the design objectives and the product reliability. The essence of this method is to find a point in design space to settle for optimized objective and reduce design risk. The $\sigma$ level of certainty optimization is lower than robust method when the design parameters under the same standard deviation. Although there are some parameters not achieved $6 \sigma$ level in robust optimization, the $\sigma$ level is high and the product failure is a small probability event.

Human body have a certain sensitivity frequency to vibration. The bodywork is also own resonance frequency. So vibration research can not avoid in vehicle component design, especially for the HSA. Figure 13 shows the vertical acceleration power spectral density of bodywork.

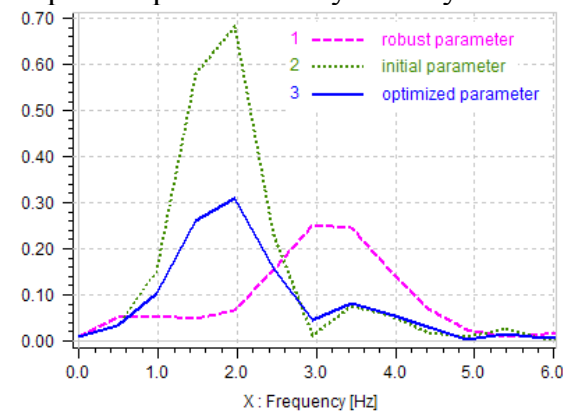

Figure 12. the bodywork's vertical acceleration power spectral density

$$
\left(\left(m / s^{2}\right)^{2} / H z\right)
$$

From the analysis of the acceleration power spectral density curves. Initial design and deterministic design make a large part of the vibration energy distributed mainly in $1 \sim 2.2 \mathrm{~Hz}$. Compared with it, the robust optimization makes the vibration energy distributed neither in human body's sensitivity frequency $0.05 \sim 0.5 \mathrm{~Hz}$ and $4 \sim 12.5 \mathrm{~Hz}$ nor in bodywork's resonance frequency $1 \sim 1.5 \mathrm{~Hz}$. This is very helpful to improve the ride comfort of vehicle.

\section{CONCLUSIONS}

The $6 \sigma$ robust method is introduced to research a HSA in this paper. Some variables are selected by sensitivity analysis. The variation of these parameters is considered. The robust parameters are calculated by $6 \sigma$ robust optimization model. The $\sigma$ level and performance curves of initial design, deterministic design and robust design are compared at last section. Compared with the deterministic method, the $6 \sigma$ robust method can increase the stability of HSA and greatly improve the ride comfort of the $1 / 4$ vehicle model.

\section{REFERENCES}

[1] Mohan D.Rao; Scott Gruenberg. Homa Torab. Measurement of Dynamic Properties of Automotive Shock Absorbers for NVH. SAE paper 1999-01-1840.

[2] H.H. Lang. A Study of the Characteristics of Automotive Dampers at High Stroking Frequencies. Ph.D. Thesis, University of Michigan, 1977.

[3] K. Morman, et. Al. A Model for the Analysis and Simulation of Hydraulic Shock Absorber Performance, Part I- Theoretical 
Development (SR-83-043), Part II-Parameter Identification and Model Validation Studies (SR-86-61). Ford Motor Company Research Staff Reports.
[4] Robert H. Swendsen; Jian-Sheng Wang. Nonuniversal Critical Dynamics in Monte Carlo Simulations. physical review letters, Volume 58, Number 2.

[5] Taguchi, G. Taguchi Methods: Research and Development. Volume 1, (1992).

TABLE I.

THE VARIABLES

\begin{tabular}{|c|c|c|c|c|c|}
\hline Parameters & PK(N/mm) & SP(mm) & FS(mm) & PS(mm) & SPK(N/mm) \\
\hline $\begin{array}{c}\text { indicated } \\
\text { structure }\end{array}$ & $\begin{array}{c}\text { Stiffness of } \\
\text { compression } \\
\text { valve disc }\end{array}$ & $\begin{array}{c}\text { Diameter of } \\
\text { rebound valve } \\
\text { disc }\end{array}$ & $\begin{array}{c}\text { Diameter of } \\
\text { by-pass valve } \\
\text { disc }\end{array}$ & $\begin{array}{c}\text { Diameter of } \\
\text { compression } \\
\text { valve disc }\end{array}$ & $\begin{array}{c}\text { Stiffness of } \\
\text { rebound valve } \\
\text { spring }\end{array}$ \\
\hline PhS(mm) & ShS(mm) & EhS(mm) & SJ1(mm) & CJ1(mm) & Pg(bar) \\
\hline $\begin{array}{c}\text { Diameter of (1) } \\
\text { in Figure5 }\end{array}$ & $\begin{array}{c}\text { Diameter of (2) } \\
\text { in Figure3 }\end{array}$ & $\begin{array}{c}\text { Diameter of } \\
\text { (4) in Figure5 }\end{array}$ & $\begin{array}{c}\text { Equivalent } \\
\text { diameter of (5) } \\
\text { in Figure3 }\end{array}$ & $\begin{array}{c}\text { Equivalent } \\
\text { diameter of (3) in } \\
\text { Figure5 }\end{array}$ & $\begin{array}{c}\text { Gas pressure of } \\
\text { oil supply } \\
\text { chamber }\end{array}$ \\
\hline
\end{tabular}

TABLE II

PARAMETERS VALUE AND $\Sigma$ LEVEL

\begin{tabular}{|c|c|c|c|c|c|c|c|c|}
\hline & \multicolumn{6}{|c|}{ Design parameters（ $\sigma$ level） } & \multicolumn{2}{|c|}{ Evaluation function } \\
\hline & $S P$ & $\operatorname{ShS}$ & $P h S$ & $F S$ & $E h S$ & $P g$ & dis & force \\
\hline Initial & $\begin{array}{c}14.8 \\
(5.42)\end{array}$ & $\begin{array}{c}4.4 \\
(0.69)\end{array}$ & $\begin{array}{c}1.76 \\
(1.57)\end{array}$ & $\begin{array}{l}22.1 \\
(2.4)\end{array}$ & $\begin{array}{c}8 \\
(4.53)\end{array}$ & $\begin{array}{c}8 \\
(>=8)\end{array}$ & $\begin{array}{c}0.038 \\
(3.4)\end{array}$ & $\begin{array}{c}3246.9 \\
(2.8)\end{array}$ \\
\hline Deterministic & $\begin{array}{c}16.8 \\
(3.86)\end{array}$ & $\begin{array}{c}2.0 \\
(2.46)\end{array}$ & $\begin{array}{c}1.45 \\
(0.86)\end{array}$ & $\begin{array}{c}23.4 \\
(1.23)\end{array}$ & $\begin{array}{c}9.21 \\
(2.67)\end{array}$ & $\begin{array}{c}7.5 \\
(1.5)\end{array}$ & $\begin{array}{l}0.035 \\
(2.31)\end{array}$ & $\begin{array}{c}3656.4 \\
(1.48)\end{array}$ \\
\hline $6 \sigma$ robust $( \pm 10 \%)$ & $\begin{array}{l}12.6 \\
(>=8)\end{array}$ & $\begin{array}{c}3.2 \\
(6.13)\end{array}$ & $\begin{array}{c}2.1 \\
(3.2)\end{array}$ & $\begin{array}{c}20.1 \\
(4.16)\end{array}$ & $\begin{array}{c}8.84 \\
(4.02)\end{array}$ & $\begin{array}{l}6.54 \\
(6.4)\end{array}$ & $\begin{array}{l}0.042 \\
(6.86)\end{array}$ & $\begin{array}{c}3156.3 \\
(5.78)\end{array}$ \\
\hline
\end{tabular}

